\title{
Diffusion Rates of Plasticizers in Polyvinyl Chloride Compounds
}

\author{
IV. Relations between Diffusion Coefficients of Plasticizers \\ and Viscosities measured by Vibrating Reed Method
}

\begin{abstract}
By Michio Kikkawa
The diffusion coefficients $(D)$ of plasticizers in polyvinyl Chloride compounds and viscosities of the compounds measured by vibrating reed method were reported in the previous papers, for the plasticizers, TCP, DOP and DOA, over the range of $20-120^{\circ} \mathrm{C}$, and $20-60$ percent plasticizer, and in this paper, the relation between them were examined. Linearity could be found between $\log D$ and $\log \eta_{50}$ at $20-50^{\circ} \mathrm{C}$. From Eyring's equation on diffusion and viscosity, and Flory-Huggins' equation of activity, the $\mu$-constants could be obtained from the dependence of $D \cdot r_{50}$ on $v_{1}$, where $v_{1}$ is volume fraction of plasticizer.
\end{abstract}

第 5 報 混和物の二次転移点, 体稆固有抵抗との関係

(1957 年 5 月 11 日受理)

吉 川充雄

要 旨 第 1 報で報告した塩化ビニル榯脂混和物中の可塑昘の㹡散速度と, 混和物の 2 次転移点および体積固有抵抗

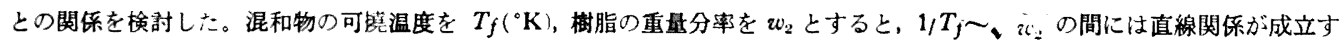

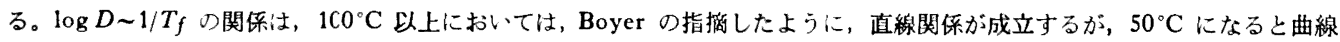

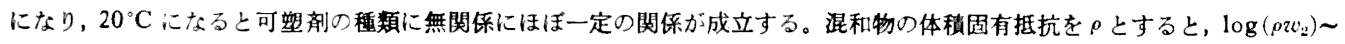
$\log D$ の間に法, 可望刘の種類に無関倸に直線関倸が成立する。

\section{1. 緒言}

可塑化塩化ピニル樹脂を電父絶緑材料として使用する場公, 特に混和物の 2 次転移点と体䅡固有抵抗に対 する可塑剤の影響が重要な問題となる。多くの場合両者は相反する倾向を示し, 而控性可塑剤は固有抵抗を 低下せしめる。この関倸を明らかにするため, 混和物中の可塑剂の昖散速度との関係を考察することとした。 なお Boyer ${ }^{11}$ はこの問題について，従来の文献に報告された研究結果をとりまとめて考察を行っているので， 筆者の測定結果について同様の考察を行い, 1,2 の点で補足することとする。

\section{2. 混和物の可撓温度との関你}

第 1 報 21 で可塑剤の昖散倸数を測定した混和物について 2 次転移点を測定した。2次転移点としては

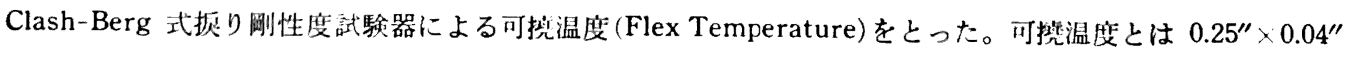
$\times 1.5^{\prime \prime}$ の短冊型試料に，5.68 $\times 10^{5} \mathrm{dyne}-\mathrm{cm}$ の偶力を作用させたときの 5 秒後の拓れ角を測定し，抔れ角が $200^{\circ}$ になるときの温度であり, $3.1 \times 10^{9} \mathrm{dyne} / \mathrm{cm}^{2}$ の岡性游に相当する ${ }^{31}$ 。

測定結界を第 1 表に示した。 
第 1 表 混和物の可慈温度, $T_{f}\left({ }^{\circ} \mathrm{C}\right)$

\begin{tabular}{|c|c|c|c|c|}
\hline \multirow{2}{*}{$\begin{array}{c}\text { 可塑㨈濃度 } \\
(\%)\end{array}$} & \multicolumn{4}{|c|}{$T_{f}\left({ }^{\circ} \mathrm{C}\right)$} \\
\hline & TCP & BBP & DOP & DOA \\
\hline 10 & 49 & 49 & 49 & 49 \\
\hline 20 & 30 & 32 & 19 & 5 \\
\hline 30 & 10 & 5 & -9 & -37 \\
\hline 40 & -8 & -15 & -35 & - \\
\hline 50 & -26 & -35 & -57 & - \\
\hline 60 & -44 & -53 & - & - \\
\hline
\end{tabular}

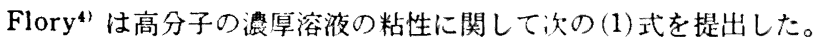

$$
\log \eta_{1}=A+B 、 w_{2}
$$

$A, B$ : 定数

$w_{2}$ ：高分子の重量分萃

Flory は単一の温度で 1 式を挨討しているが，温度が没化した場合は次の(2)式が成立するものと考えら れる。

$$
\begin{gathered}
\log \eta=A+B 、 w_{2}+\frac{E_{v}}{R T} \\
E_{v}: \text { 粘性の活性化エネルギー } \\
R: \text { 気体定数 }
\end{gathered}
$$

いま 2 次転移点とはナがある一定の值に達する温度であると仮定し，さらに $E_{1}$ が $w_{2}$ に無関係に一定で ある上仮定すればは式が導かれる。

$$
\begin{aligned}
& 、 w_{2}= A^{\prime}-\frac{E_{v}}{B R T_{f}} \\
& A^{\prime}=\frac{\left(\log r_{f}\right) T \cdot T_{f}-A}{B}=\text { 定数 } \\
& T_{f} \cdots \text { 可䒨温度 }\left({ }^{\circ} \mathrm{K}\right)
\end{aligned}
$$

Boyer, Spencer ${ }^{51}$ は可塑凨を含む高分子の 2 次枟移点に関する従来の文献をまとめて，(3)式の関倸がみ 芑とに成立することを㬰証した。ただ(3)式を(2)式から導くときに必要な仮定はいずれも疑問があると思わ れるので, Boyer" も述へているように（3)式は測定結果をまとめ るための単なる実験式とみなすべきであろう。筡者の今回の測定結 果においても, 可撓温度 $T_{f}\left({ }^{\circ} \mathrm{K}\right)$ の逆数と $\sqrt{ } w_{2}$ の間には, 第 1 図 に示すようにみごとな植線関倸が成立する。(3)式が成立する理由 は今後の研究にまたなければならないが, 第 1 図の直線の傾斜は可 塑冎剂率を比較するのに便利であって，傾斜の大きい方が勃率が 大であることを示している。

さらに Boyer ${ }^{1)}$ は可塑戍の抎散係数 $D$ と混和物の粘性 $\eta$ の間に, $D \cdot \eta=$ const の関係を仮定し，(1)式と(3)式から次の(4)式が成立す ることを述べ, Liebhafsky ら ${ }^{6)}$ の TCP, 20〜60"う, $145^{\circ} \mathrm{C}$ におけ るDの值と, Boyer, Spencer ${ }^{5)}$ の報告した脆化温度, $T_{B}\left({ }^{\circ} \mathrm{K}\right)$ の 間に(4)式が成立することを実証した。

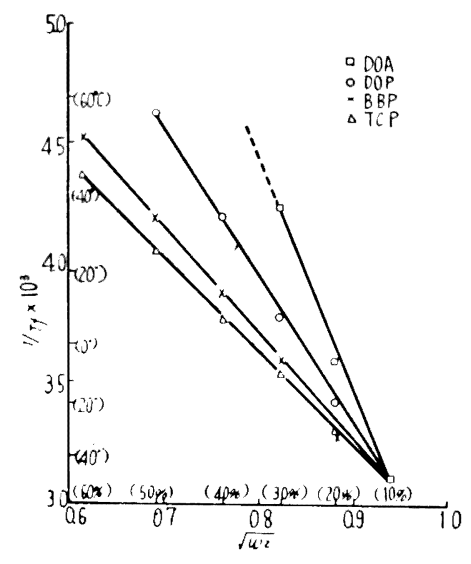

第 1 図 $1 / T_{f} \sim \sqrt{ } w_{2}$ の関倸 


$$
\begin{array}{r}
\log D=\alpha+\frac{\beta}{T_{B}} \\
\alpha, \beta: \text { 定数 }
\end{array}
$$

第 1 表に示した可撓温度について $1 / T_{f}$ を横軸にとり， $\log D$ を綎軸にとると第 2 図が得られる。すなわち $100^{\circ} \mathrm{C}$ 以上 $\left(100^{\circ} \mathrm{C}\right.$ の TCP 配合のみは例外であるが)の温度で $D$ を測定すれば(4)式は成立する。 $50^{\circ} \mathrm{C}$ においては直線 関倸からずれる。 $20^{\circ} \mathrm{C}$ になると各可塑剤の曲線が 1 本 に近つきき, 可撜温度と拡散係数の間に共通な関係が成立 するようである。この変化の内容を説明することは現在 のところ困難であるが, $20^{\circ} \mathrm{C}$ の $D$ の值から可致温度の 概約の值が求められるので実用上便利である。

\section{3. 混和物の体積固有抵抗との関係}

ピニル混和物の電気伝導度は不純物として存在するイ オンの移動によるものと考えられるが，この不純物は主 として樹脂からくるものと考えられる ${ }^{11,7}$ 。したがって

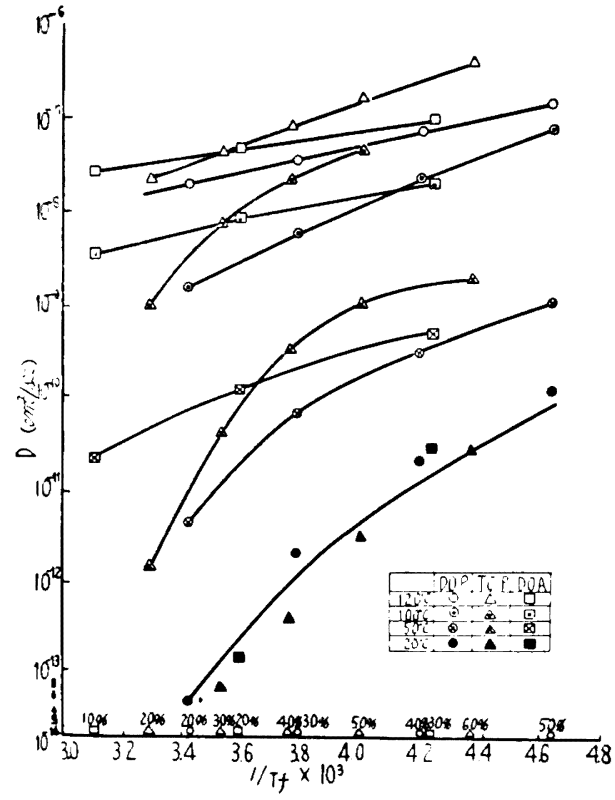

第 2 図 $\log D \sim 1 / T_{f}$ の関係

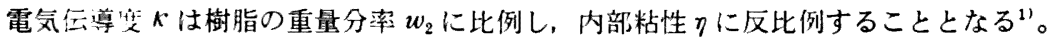

$$
\begin{aligned}
\kappa & \propto \frac{w_{2}}{\eta} \\
& \therefore \eta \propto: w_{2}
\end{aligned}
$$

$\rho$ ：体稍固有抵抗

クについて(1)式が成立すれば次の (7)式が成立することとなる。

$$
\begin{aligned}
& \log \left(\rho w_{2}\right)=\sigma+: \sqrt{w_{2}} \\
& \sigma, \tau: \text { 定数 }
\end{aligned}
$$

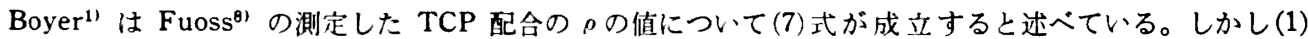

\begin{tabular}{|c|c|c|c|c|}
\hline \multirow{2}{*}{$\begin{array}{c}\text { 可塑剤濃度 } \\
(\%)\end{array}$} & \multicolumn{4}{|c|}{$\rho(\Omega-\mathrm{cm})$} \\
\hline & TCP & BBP & DOP & DOA \\
\hline 10 & - & - & - & $2.6 \times 10^{18}$ \\
\hline 20 & $7.5 \times 10^{13}$ & - & $8.3 \times 10^{18}$ & $8.1 \times 10^{11}$ \\
\hline 30 & $1.7 \times 10^{18}$ & $1.4 \times 10^{12}$ & $1.4 \times 10^{12}$ & $3.2 \times 10^{10}$ \\
\hline 40 & $2.5 \times 10^{11}$ & $9.6 \times 10^{10}$ & $1.1 \times 10^{11}$ & $1.3 \times 10^{10}$ \\
\hline 50 & $2.8 \times 10^{10}$ & $1.9 \times 10^{10}$ & $3.8 \times 10^{10}$ & $1.3 \times 10^{\theta}$ \\
\hline 60 & - & $1.3 \times 10^{10}$ & $1.1 \times 10^{10}$ & - \\
\hline
\end{tabular}
式が一般に広い篹囲にわたって成立するとは考えられないので(7)式も疑わしい。

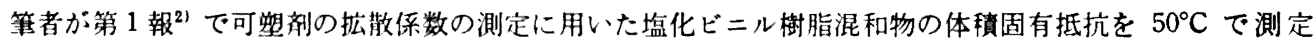
した結果を第 2 表に示した。

第 2 表 混和物の体楮固有抵抗 $\rho$

$\left(50^{\circ} \mathrm{C}\right)$

（测定法は JIS K 6723-1955に洀し直偏法により水銀電極を用いて行った。） 


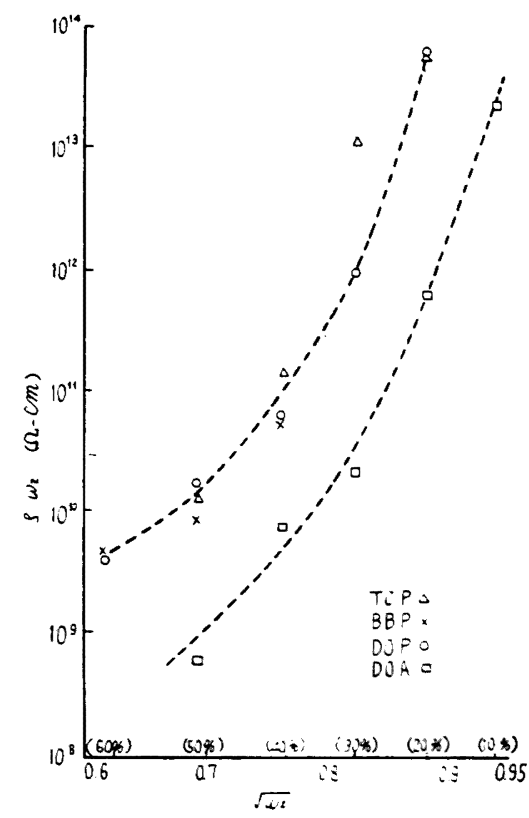

第 3 図 $\log \left(\rho w_{2}\right) \sim \sqrt{w_{2}}$ の関倸

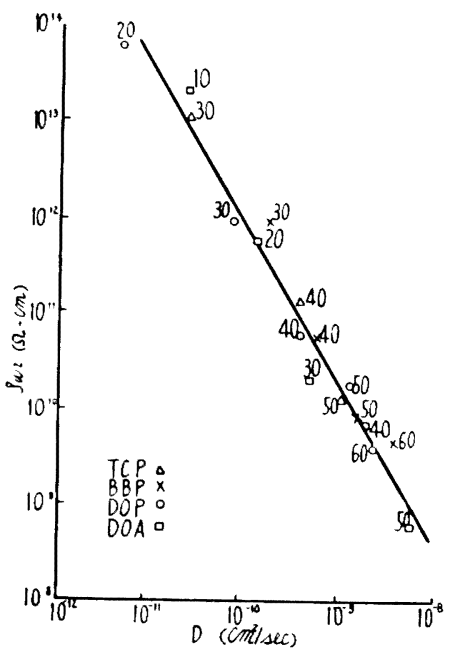

第 4 図 $\log \left(\rho w_{2}\right) \sim \log D$ の関係

第 3 図に $\log \left(\rho w_{2}\right) \sim \sqrt{w_{2}}$ の関係を示したが, 可塑剤濃度が低い部分ではほぼ直線関係が成立するようで あるが，広い範囲では成立しない。第 4 図に $50^{\circ} \mathrm{C}$ における $D$ と。について, $\log \left(\rho w_{2}\right) \sim \log D$ の関倸を示 したが，この場合は可塑剤の種類によらず直線関倸が成立する。(第 4 図中の数字は可塑剤濃度 (\%)を示す。)

\section{4. 結言}

混和物の可撓温度を $T_{f}\left({ }^{\circ} \mathrm{K}\right)$, 樹脂の重量分率を $w_{2}$ とすると, $1 / T_{f} \sim \sqrt{ } w_{2}$ の問には等者の測定結果にお いても直線関倸が成立する。 $\log D \sim 1 / T_{f}$ の関倸は, $100^{\circ} \mathrm{C}$ 以上においては, Boyer の指摘したよ5に, 直 線関係が成立するが， $50^{\circ} \mathrm{C}$ になると曲線となり，20ㄷ になると可塑剤の種類に無関係にほぼ一定の関倸が 成立する。混和物の体積固有抵抗を $\rho$ とすると, $\log \left(\rho w_{2}\right) \sim \log D$ の間には可塑剤の種類に無関倸に直線関 倸が成立する。したがってイオンの移動に関連する内部粘性を可塑郕の拡散保数で間接的に測定できると考 えられるので, 混和物の内部粘性が関倸する事項を考察する場合に, 可塑郕の昖散係数を測定することは重 要な意義があると考えられる。

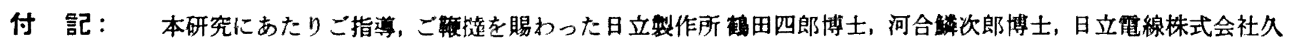

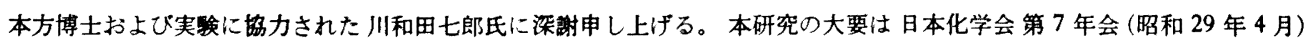
で報告した。

\section{文献}

1) R.F. Boyer: J. Appl. Phys., 20, 540(1949)

2) 吉川：本誌に投稿中

3) R.F. Clash and R.M. Berg: Ind. Eng. Chem., 34, 1218(1942)

4) P. J. Flory: J. Phys. Chem., 46, 870(1942) 
5) R.F. Boyer and R.S. Spencer: J. Appl. Phys., 16, 594 (1945) ; J. Polym. Sci., 2, 157(1947)

6) H.A. Liebhafsky, A.L. Marshall and F.H. Verhoek: Ind. Eng. Chem., 34, 704(1942)

7) 後藤：高化, 9 (91) 411 (1952)

8) R.M. Fuoss: J. Am. Chem. Soc., 61, 2334 (1939)

\section{Diffusion Rates of Plasticizers in Polyvinyl Chloride Compounds}

\section{Relations to Second-order Transition Temperatures and Volume Resistivities of Compounds}

\section{By Michio Kikkawa}

In the previous paper, the diffusion coefficients $(D)$ of plasticizers in the polyvinyl chloride compounds were reported, for the plasticizers, TCP, DOP and DOA, over the range of $20-120^{\circ} \mathrm{C}$, and 20-60 percent plasticizer. In this paper, the relations were examined between $D$ and flex temperatures and volume resistivities of the compounds. The reciprocal of flex temperatures $\left(T_{f}{ }^{\circ} \mathrm{K}\right)$ is proportional to $\sqrt{w_{2}}$, where $w_{2}$ is weight fraction of resin. If $D$ was measured at over $100^{\circ} \mathrm{C}$, linearity was found between $1 / T_{f}$ and $\log D$, but not linear at lower temperatures, and at $20^{\circ} \mathrm{C}$, there seemed to exist a certain general relationship between them. A linear relationship, common to all plasticizers tested, was found between $\log \left(\rho w_{2}\right)$ and $\log D$, where $\rho$ is the volume resistivity of the compound. 